\title{
Fitossociologia e estrutura do estrato arbóreo de um reflorestamento com espécies nativas em Mogi-Guaçu, SP, Brasil ${ }^{1}$
}

\author{
Michel Anderson Almeida Colmanetti ${ }^{2,3}$ e Luiz Mauro Barbosa ${ }^{2}$
}

Recebido: 29.04.2013; aceito: 6.08 .2013

\begin{abstract}
Phytosociology and structure of woody overstory from a reforestation with native species at Mogi-Guaçu, São Paulo State, Brazil). We have developed a phytosociological survey on tree stratum (woody overstory) from a nine-year-old reforestation at a Private Reserve of Natural Heritage, São Paulo State, Brazil. We evaluated all the specimens from the tree stratum (Circumference at Breast Height $(\mathrm{CBH}) \geq 15 \mathrm{~cm})$. They were obtained from 20 subplots $(12.5 \times 18 \mathrm{~m})$, located at 20 permanent plots. We evaluated 364 specimens from the tree stratum and found 76 species, 63 genera, and 24 families at a 0.45 ha area. The canopy height ranged from 5 to $11 \mathrm{~m}$. The estimated basal area was $18.29 \mathrm{~m}^{2} \mathrm{ha}^{-1}$, and the pioneer species contributed with 69.2 percent of the total plant species. Both basal area and average height parameters increased throughout time, whereas the diversity did not. The diversity index was considered high for a reforestation.
\end{abstract}

Key words: ecological restoration, high diversity, reforestation

RESUMO - (Fitossociologia e estrutura do estrato arbóreo de um reflorestamento com espécies nativas em Mogi-Guaçu, SP, Brasil). Foi realizado um estudo fitossociológico do estrato arbóreo, de um reflorestamento com nove anos após o plantio, na Reserva Particular do Patrimônio Natural Parque Florestal São Marcelo, em Mogi-Guaçu, SP, Brasil. Analisaram-se todos os indivíduos do estrato arbóreo com perímetro a $1,3 \mathrm{~m}$ de altura do solo $\geq 15 \mathrm{~cm}$, obtidos em amostragens realizadas em 20 subparcelas $(12,5 \times 18 \mathrm{~m})$, instaladas em 20 parcelas permanentes. Obtiveram-se, no levantamento, 364 indivíduos pertencentes a 76 espécies, de 63 gêneros e 24 famílias, para uma área total de 0,45 ha. O dossel variou, predominantemente, entre cinco e $11 \mathrm{~m}$ de altura. A área basal foi estimada em 18,29 $\mathrm{m}^{2} \mathrm{ha}^{-1}$, sendo que as espécies pioneiras contribuíram com 69,2\%. Parâmetros como a área basal e altura média aumentaram, enquanto a diversidade não variou ao longo do tempo. A diversidade encontrada foi considerada alta para um reflorestamento.

Palavras-chave: alta diversidade, reflorestamento, restauração ecológica

\section{Introdução}

O Estado de São Paulo possui ferramentas legais, como as resoluções da Secretaria do Meio Ambiente de São Paulo - SMA, que norteiam a restauração ecológica. Essas resoluções são baseadas em reuniões, workshops e simpósios desenvolvidos na última década, e alicerçadas no conhecimento empírico e científico sobre restauração, tanto no Brasil quanto no exterior (Barbosa et al. 2011). As resoluções paulistas estabelecem o uso de espécies com diferentes síndromes de dispersão e de diferentes classes sucessionais, com uma diversidade de acordo com o tipo de formação florestal, considerando, inclusive, as listas de espécies arbóreas ameaçadas de extinção.
Aronson (2010) ressaltou que as orientações para a restauração, presentes na legislação do Estado de São Paulo, colocam o Brasil entre os poucos países que possuem legislação voltada à restauração. Aronson et al. (2011) destacaram ainda que o Brasil, especificamente o Estado de São Paulo, é o único país que orienta, por meio da sua legislação, as técnicas utilizadas, diretrizes e as normas mínimas exigidas para a restauração.

Um ponto relevante para a restauração ecológica, conforme previsto pela Resolução SMA no 8/2008, corresponde ao uso de alta riqueza de espécies nativas (80 ou mais espécies arbóreas) nos reflorestamentos. Essa iniciativa é bastante plausível, considerando que a maioria dos ecossistemas brasileiros é formada por um

1. Parte da Dissertação de Mestrado do primeiro Autor

2. Instituto de Botânica, Coordenação Especial de Restauração de Áreas Degradadas - CERAD, Caixa Postal 68041, 04045-972 São Paulo SP, Brasil

3. Autor para correspondência: michelcolmanetti@gmail.com 
grande número de espécies (Martins et al. 2012). Essa iniciativa pretende proporcionar o estabelecimento e a manutenção desses reflorestamentos ao longo do tempo (Barbosa \& Barbosa 2007, Rodrigues et al. 2009, Rodrigues et al. 2011, Barbosa et al. 2012).

A real situação desses reflorestamentos, no entanto, se caminham para o sucesso ou se merecem novas intervenções, só pode ser conhecida a partir do momento em que se avalia seu estado de desenvolvimento, durante o processo de restauração. Nesse contexto, avaliar e monitorar essas áreas permite verificar se o objetivo foi alcançado, possibilitando, inclusive, redefinir a trajetória ambiental das áreas em processo de restauração, caso se apresentem em declínio, ou com poucos sinais de sustentabilidade, ao longo do tempo (Brancalion et al. 2012).

Diversos estudos têm avaliado o desenvolvimento de reflorestamentos implantados com espécies nativas, com base em diferentes parâmetros relacionados com as florestas em formação. Vários estudos têm sido realizados com base, principalmente, na composição florística e estrutura da vegetação arbórea (Souza \& Batista 2004, Damasceno 2005, Melo \& Durigan 2007, Castanho 2009). No entanto, outros parâmetros, também de grande importância, têm sido avaliados, como a regeneração natural, incluindo as epífitas e lianas, além de banco e chuva de sementes (Siqueira 2002, Damasceno 2005, Barbosa \& Piso 2006), e até a fauna associada à vegetação de reflorestamentos (Silveira et al. 2011, Trevelin et al. 2013). Todavia, ressalta-se que analisar os parâmetros de reflorestamentos, entre eles a estrutura da vegetação, e utilizar indicadores adequados que expressem, da melhor forma, a real situação de uma área, é fundamental para verificar se as áreas restauradas atingiram os seus objetivos (Brancalion et al. 2012).

A Reserva Particular do Patrimônio Natural (RPPN) Parque Florestal São Marcelo, local do presente estudo, tem origem a partir de um reflorestamento implantado com alta riqueza de espécies nativas, onde foi realizado um levantamento das espécies arbóreas, dois anos e meio após o plantio (Mandetta 2007). O presente estudo é uma abordagem que faz parte de um estudo mais abrangente, realizado na área nove anos após o plantio, que reflete a situação atual do reflorestamento na referida RPPN.

O objetivo deste trabalho foi avaliar e analisar a estrutura e composição florística dessa RPPN, obtidas a partir de um reflorestamento, localizado no
Parque São Marcelo, Mogi-Guaçu/SP, visando a obter informações importantes sobre reflorestamentos com alta diversidade de espécies nativas.

\section{Material e Métodos}

Os estudos foram desenvolvidos na Reserva Particular do Patrimônio Natural (RPPN) Parque Florestal São Marcelo, pertencente à empresa International Paper do Brasil LTDA. A RPPN possui em 240 ha, sendo formada a partir de um reflorestamento com espécies nativas, realizado em 2002. A metodologia adotada na implantação desse reflorestamento constituiu-se no plantio de espécies nativas arbóreas com uma alta riqueza, 100 espécies. De acordo com a classificação adotada para o presente estudo, a proporção das espécies plantadas foi de $56 \%$ de não pioneiras, $37 \%$ de pioneiras e $7 \%$ de espécies não classificadas ou exóticas. Observa-se que as espécies exóticas, plantadas no momento do plantio, estavam identificadas apenas em nível de gênero, sendo as mesmas identificadas quando adultas, durante o presente estudo. Para o plantio, não há informação sobre a proporção de indivíduos por espécie, porém, sabe-se que não ultrapassou $20 \%$ de indivíduos de uma mesma espécie. A distribuição das espécies, no momento do plantio, ocorreu ao acaso, sendo alternadas nas linhas espécies pioneiras e não pioneiras. Utilizaram-se um espaçamento de $3,0 \times 2,5 \mathrm{~m}$, e uma densidade de 1.333 mudas ha $^{-1}$.

A RPPN está localizada no município de Mogi-Guaçu (SP), próximo ao km 169 da Rodovia SP-340. Segundo Kronka (2005), a vegetação original da região em estudo é composta de Floresta Estacional Semidecídua, com ocorrência de Cerrado lato sensu (Savana Gramíneo-lenhosa). O clima da região, segundo o sistema de Köppen (1948), é classificado como Cwa (temperado quente com estiagem no inverno). A propriedade era destinada, no passado, ao plantio de culturas de ciclo anual, semiperenes, como cana-de-açúcar, e perenes, como café, citros, além de pastagem. Após a aquisição da área pela International Paper em 1995, a área foi destinada unicamente ao plantio de Eucalyptus sp., até o ano de 2002. Nesse mesmo ano, 240 ha foram destinados à implantação da RPPN.

As áreas circunvizinhas à RPPN são compostas por propriedades rurais, incluindo o Horto Mogi-Guaçu pertencente à empresa, destinado ao plantio comercial de Eucalyptus sp., existindo pequenos fragmentos florestais representados por faixas ciliares de vegetação nativa remanescente. As matas ciliares dos 
rios Mogi-Guaçu e Mogi-Mirim, que se encontram dentro da propriedade, foram implantadas entre 1996 e 1998, com baixa diversidade específica (cerca de 30 espécies arbóreas) e o fragmento florestal com maior expressão está localizado numa propriedade vizinha, pertencente a terceiros, a uma distância aproximada de $10 \mathrm{~km}$ da RPPN.

Dentro da área reflorestada de 240 hectares, foram implantadas 40 parcelas experimentais permanentes, com dimensões de $36 \times 62,5 \mathrm{~m}$, das quais 20 foram utilizadas para o presente estudo (figura 1). Em cada parcela foram realizadas as investigações, de modo a avaliar as espécies plantadas, bem como as regenerantes, incluindo todos os indivíduos com Circunferência a Altura do Peito (CAP) maior ou igual a $15 \mathrm{~cm}$. A amostragem dos indivíduos arbóreos foi realizada em parcelas onde já ocorreram estudos anteriores, realizados por Mandetta (2007). Foram escolhidas 20 parcelas, de modo a contemplar as duas formações de solos existentes na área (Latossolo e Argissolo). Para essa amostragem, cada parcela foi dividida em 10 subparcelas de $18 \times 12,5 \mathrm{~m}\left(225 \mathrm{~m}^{2}\right)$. Dessas 10 subparcelas, uma foi escolhida de modo sistematizado, somando 20 subparcelas e totalizando uma área amostral total de 0,45 ha.
Foram obtidas as medidas dendrométricas, altura e diâmetro, para os indivíduos arbóreos, com $\mathrm{CAP} \geq 15 \mathrm{~cm}$ encontrados nas linhas do plantio. Todos os indivíduos foram marcados com placas de identificação. No caso dos indivíduos com mais de um tronco, foram mensurados os perímetros de todos os troncos com $\mathrm{CAP} \geq 15 \mathrm{~cm}$. As estimativas de altura foram obtidas com a utilização de trena eletrônica (LEICA DISTO ${ }^{\mathrm{TM}}$ D8), e as medidas de circunferência, com a utilização de fita métrica.

Destaca-se que Mandetta (2007) também realizou amostragem em 20 subparcelas $(18 \times 12,5 \mathrm{~m})$, obtidas a partir de 20 parcelas permanentes, totalizando uma área amostral total de 0,45 ha. Ressalta-se que as parcelas permanentes avaliadas pela autora correspondem às mesmas parcelas do presente estudo, no entanto, as subparcelas não são as mesmas entre os dois estudos. Em seu levantamento, Mandetta (2007) avaliou todos os indivíduos arbóreos das linhas de plantio, bem como os indivíduos arbóreos regenerantes com altura $\geq 1,0 \mathrm{~m}$.

A identificação das espécies ocorreu na área e aquelas que não puderem ser identificadas dessa forma, foram herborizadas e encaminhadas ao Herbário do Instituto de Botânica de São Paulo, para

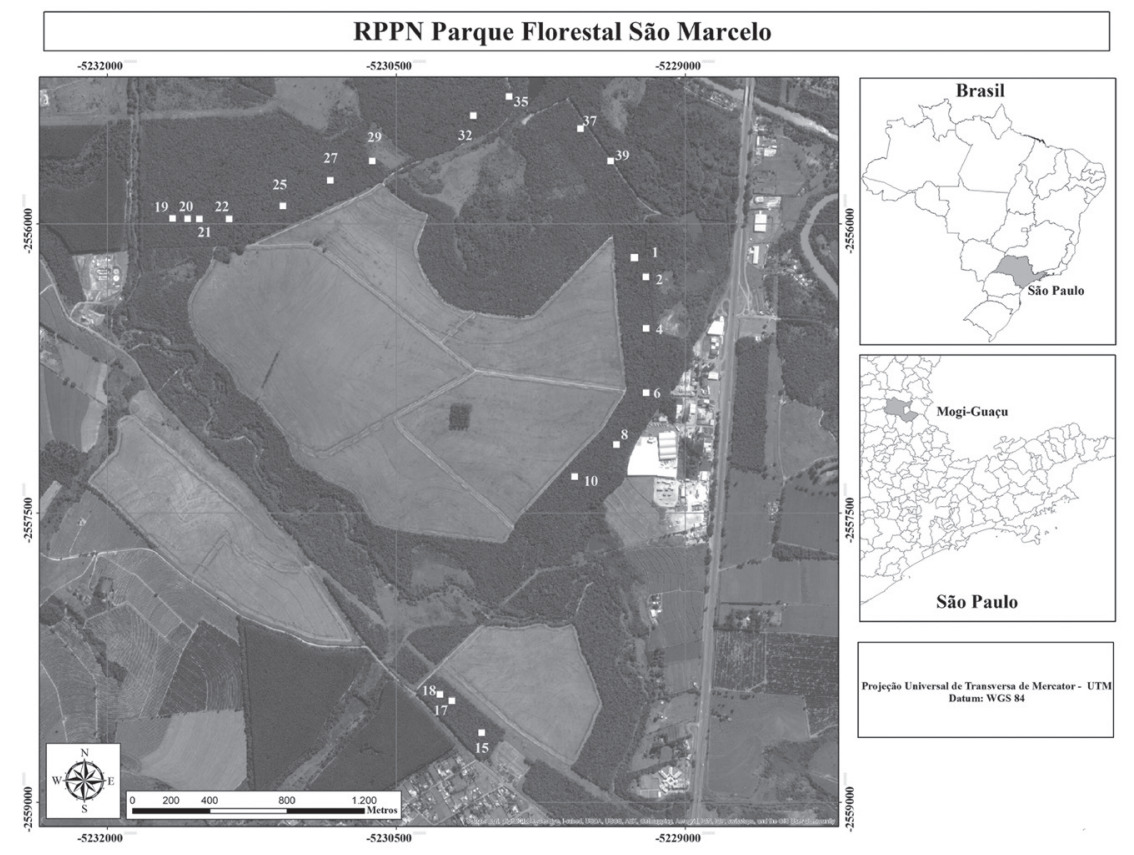

Figura 1. Representação da RPPN Parque Florestal São Marcelo, inserida no município de Mogi-Guaçu, SP, Brasil. As subparcelas amostrais estão destacadas, sendo que: 11 subparcelas $(1,2,19,20,21,22,25,27,29,37$ e 39) correspondem ao Argissolo, e nove subparcelas (4, $6,8,10,15,17,18,32$ e 35) correspondem ao Latossolo.

Figure 1. Representation of PRNP Parque Florestal São Marcelo, inserted in Mogi-Guaçu county, São Paulo State, Brazil. 11 sub-plots correspond to Argisol $(1,2,19,20,21,22,25,27,29,37$, and 39) and nine sub-plots correspond to Latossol (4, 6, 8, 10, 15, 17, 18, 32, and 35). 
identificação por meio de consulta a especialistas. As espécies foram organizadas em listagem por famílias, de acordo com o Angiosperm Phylogeny Group (APG III 2009). A nomenclatura foi atualizada segundo Forzza et al. (2012) e listagem da base de dados do site W3tropicos do Missouri Botanical Garden, disponível on-line (http://www.tropicos. org/). Foram coletados espécimes mais relevantes e de interesse, para incorporação no Herbário SP (Instituto de Botânica de São Paulo), seguindo técnicas tradicionais (Mori et al. 1985).

Os grupos sucessionais das espécies foram classificado em pioneiros e não pioneiros, segundo a lista indicada pela Resolução SMA n ${ }^{\circ} / 2008$ e disponível no site do Instituto de Botânica de São Paulo (http://www.ibot.sp.gov.br). As espécies que não constaram nesta lista foram classificadas pelo pesquisador Eduardo Luís Martins Catharino. As espécies exóticas e as espécies identificadas apenas em nível de gênero não foram classificadas.

Para a classificação da síndrome de dispersão das espécies, em anemocóricas, zoocóricas e autocóricas, também utilizou-se a lista estabelecida pela Resolução SMA nº 8/2008. As espécies que não constaram nesta lista foram igualmente classificadas pelo pesquisador Eduardo Luís Martins Catharino. As espécies identificadas em nível de gênero não foram classificadas.

A estrutura da comunidade foi descrita a partir dos parâmetros fitossociológicos, como Frequência Relativa (FrR), Abundância Relativa (AR) e Dominância Relativa (DoR), Valores de Cobertura e Importância (VC e VI), segundo Mueller-Dombois \& Ellenberg (1974).

A diversidade foi calculada pelo índice de Shannon (H'), com base logarítmica natural, e também pelo índice de Simpson (Simpson 1949). Para obter uma relação direta entre diversidade e o índice de Simpson, o mesmo foi subtraído do seu valor máximo, 1, conforme descrito por Magurran (2004). Também foi calculada a equitatividade pelo índice de Pielou (J') (Pielou 1969, 1975).

\section{Resultados}

No levantamento fitossociológico da área amostral (0,45 ha), foram encontrados 364 indivíduos com CAP $\geq 15 \mathrm{~cm}$, sendo listadas 76 espécies, 63 gêneros e 24 famílias (tabela 1). Entre essas espécies, 70 são nativas regionais e seis são exóticas. As famílias que apresentaram maior riqueza foram Fabaceae (20 espécies), Bignoniaceae (10) e Anacardiaceae (sete).
Foram amostradas duas espécies enquadradas, segundo Mamede et al. (2007), como "vulneráveis": Myracrodruon urundeuva e Myroxylon peruiferum, e três espécies enquadradas como "quase ameaçadas": Aspidosperma polyneuron, Copaifera langsdorffii e Balfourodendron riedelianum.

$\mathrm{Na}$ classificação das espécies, de acordo com o grupo sucessional: $52,6 \%$ são espécies não pioneiras, $36,8 \%$ são espécies pioneiras, $7,9 \%$ são classificadas como espécies exóticas, e 2,6\% não foram classificadas (N.C). Em relação à classificação dos indivíduos quanto ao grupo sucessional, foram obtidos os seguintes valores: $49,2 \%$ pioneiros, $40,9 \%$ não pioneiros, $9,3 \%$ exóticos e $0,5 \%$ não foram classificados.

As espécies levantadas no presente estudo foram comparadas, quanto ao grupo sucessional, com outro estudo desenvolvido na mesma área por Mandetta (2007), dois anos e meio após o plantio (figura 2). Para que fosse possível realizar a comparação entre os estudos, a lista de espécies levantadas por Mandetta (2007) foi atualizada quanto à nomenclatura, e as espécies foram classificadas, quanto ao grupo sucessional, de acordo com o critério adotado para o presente estudo. A proporção de espécies, classificadas de acordo com o grupo sucessional, foi semelhante para os dois estudos.

$\mathrm{Na}$ classificação da síndrome de dispersão das espécies: $39,5 \%$ são anemocóricas, $35,5 \%$ são zoocóricas e 21,1\% são autocóricas. Em relação à classificação dos indivíduos: 47\% são zoocóricos, $31,9 \%$ são anemocóricos e 20,3\% são autocóricos.

A floresta variou, em altura, de 2,9 a 17,1 m, para o estrato arbóreo; no entanto, a maioria dos indivíduos predominou entre 5,1 e $11 \mathrm{~m}$ (figura 3 ). A altura média foi de $8,43 \mathrm{~m}$ e a mediana, $8,3 \mathrm{~m}$. Os indivíduos emergentes, considerados aqueles com altura maior que 14 metros, pertenceram às espécies Schizolobium parahyba e Croton floribundus.

A área basal dos indivíduos amostrados variou entre $17,91 \mathrm{~cm}^{2}\left(0,0018 \mathrm{~m}^{2}\right)$ a $1188,22 \mathrm{~cm}^{2}\left(0,1188 \mathrm{~m}^{2}\right)$ (figura 4). A média foi $226,47 \mathrm{~cm}^{2}$ e a mediana $122,41 \mathrm{~cm}^{2}$. A área basal foi estimada em $18,29 \mathrm{~m}^{2} \mathrm{ha}^{-1}$, para uma densidade estimada de 809 indivíduos ha ${ }^{-1}$. As espécies pioneiras contribuíram com $69,2 \%$ da área basal, enquanto as não pioneiras contribuíram com $27,7 \%$ do total.

A espécie Inga vera subsp. affinis apresentou, destacadamente, o maior valor de importância (VI) em relação às outras espécies, com base na análise dos parâmetros fitossociológicos (tabela 2). As espécies 
Tabela 1: Espécies arbóreas amostradas nas 20 subparcelas amostrais da RPPN Parque São Marcelo, Mogi-Guaçu, SP, Brasil. **Espécies exóticas. Anemo: Anemocórica; Auto: Autocórica; Zoo: Zoocórica; N.C.: Não classificada.

Table 1: Woody species obtained from 20 sub-plots located at RPPN Parque São Marcelo, Mogi-Guaçu, São Paulo State, Brazil. ** Exotic species. Anemo: Anemochoric species; Auto: Autochoric species; Zoo: Zoochoric species; N.C.: Not Classified.

\begin{tabular}{|c|c|c|c|}
\hline Família/Espécie & Grupo Ecológico & Síndrome de Dispersão & Origem \\
\hline \multicolumn{4}{|l|}{ Anacardiaceae } \\
\hline Astronium fraxinifolium Schott & Não Pioneira & Anemo & Plantio \\
\hline Astronium graveolens Jacq. & Não Pioneira & Anemo & Plantio \\
\hline Lithrea molleoides (Vell.) Engl. & Pioneira & Zoo & Plantio \\
\hline Myracrodruon urundeuva Allemão & Não Pioneira & Auto & Plantio \\
\hline Schinus molle L. & Pioneira & Zoo & Plantio \\
\hline Schinus terebinthifolius Raddi & Pioneira & Zoo & Plantio \\
\hline Tapirira guianensis Aubl. & Não Pioneira & Zoo & Plantio \\
\hline \multicolumn{4}{|l|}{ Apocynaceae } \\
\hline Aspidosperma cylindrocarpon Müll. Arg. & Não Pioneira & Anemo & Plantio \\
\hline Aspidosperma polyneuron Müll. Arg. & Não Pioneira & Anemo & Plantio \\
\hline Tabernaemontana hystrix Steud. & Pioneira & Zoo & Plantio \\
\hline \multicolumn{4}{|l|}{ Asteraceae } \\
\hline Gochnatia polymorpha (Less.) Cabrera & Pioneira & Anemo & Plantio \\
\hline \multicolumn{4}{|l|}{ Bignoniaceae } \\
\hline Handroanthus heptaphyllus (Vell.) Mattos & Não Pioneira & Anemo & Plantio \\
\hline Handroanthus impetiginosus Mattos & Não Pioneira & Anemo & Plantio \\
\hline Handroanthus ochraceus (Cham.) Mattos & Não Pioneira & Anemo & Plantio \\
\hline Handroanthus serratifolius (A.H. Gentry) S.Grose & Não Pioneira & Anemo & Plantio \\
\hline Handroanthus sp. & N.C. & N.C. & N.C. \\
\hline Jacaranda cuspidifolia Mart. & Não Pioneira & Anemo & Plantio \\
\hline Jacaranda mimosifolia D. Don** & Exótica & Anemo & Plantio \\
\hline Tabebuia roseoalba (Ridl.) Sandwith & Não Pioneira & Anemo & Plantio \\
\hline Tecoma stans (L.) Juss. ex Kunth** & Exótica & Anemo & Regenerante \\
\hline Zeyheria tuberculosa (Vell.) Bureau ex Verl. & Não Pioneira & Anemo & Plantio \\
\hline \multicolumn{4}{|l|}{ Boraginaceae } \\
\hline Cordia abyssinica R.Br. ex A. Rich.** & Exótica & Zoo & Plantio \\
\hline Cordia trichotoma (Vell.) Arráb. ex Steud. & Não Pioneira & Zoo & Plantio \\
\hline \multicolumn{4}{|l|}{ Euphorbiaceae } \\
\hline Alchornea glandulosa Poepp. \& Endl. & Pioneira & Zoo & Regenerante \\
\hline Croton floribundus Spreng. & Pioneira & Auto & Plantio \\
\hline Croton urucurana Baill. & Pioneira & Auto & Plantio \\
\hline Mabea fistulifera Mart. & Pioneira & Auto & Plantio \\
\hline \multicolumn{4}{|l|}{ Fabaceae } \\
\hline Albizia niopoides (Spruce ex Benth.) Burkart & Pioneira & Auto & Plantio \\
\hline Anadenanthera colubrina (Vell.) Brenan & Não Pioneira & Auto & Plantio \\
\hline Anadenanthera colubrina var. cebil (Griseb.) Altschul & Não Pioneira & Auto & Plantio \\
\hline Bauhinia sp. & N.C. & N.C. & Plantio \\
\hline Cassia leptophylla Vogel & Não Pioneira & Auto & Plantio \\
\hline
\end{tabular}


Tabela 1 (continuação)

\begin{tabular}{|c|c|c|c|}
\hline Família/Espécie & Grupo Ecológico & Síndrome de Dispersão & Origem \\
\hline Copaifera langsdorffii Desf. & Não Pioneira & Zoo & Plantio \\
\hline Enterolobium contortisiliquum (Vell.) Morong & Não Pioneira & Auto & Plantio \\
\hline $\begin{array}{l}\text { Hymenaea courbaril L. var. stilbocarpa (Hayne) Y.T. } \\
\text { Lee \& Langenh. }\end{array}$ & Não Pioneira & Zoo & Plantio \\
\hline Inga vera subsp. affinis (DC.) T. D. Penn. & Pioneira & Zoo & Plantio \\
\hline Machaerium aculeatum Raddi & Pioneira & Anemo & Plantio \\
\hline Mimosa bimucronata (DC.) Kuntze & Pioneira & Auto & Plantio \\
\hline Myroxylon peruiferum L.f. & Não Pioneira & Anemo & Plantio \\
\hline Parapiptadenia rigida (Benth.) Brenan & Não Pioneira & Auto & Plantio \\
\hline Peltophorum dubium (Spreng.) Taub. & Pioneira & Auto & Plantio \\
\hline Poecilanthe parviflora Benth. & Não Pioneira & Auto & Plantio \\
\hline Pterocarpus rohrii Vahl & Não Pioneira & Anemo & Plantio \\
\hline Pterogyne nitens Tul. & Não Pioneira & Anemo & Plantio \\
\hline Schizolobium parahyba (Vell.) Blake & Pioneira & Anem & Plantio \\
\hline Senegalia polyphylla (DC.) Britton \& Rose & Pioneira & Auto & Plantio \\
\hline Senna multijuga (Rich.) H.S. Irwin \& Barneby & Pioneira & Auto & Plantio \\
\hline \multicolumn{4}{|l|}{ Lamiaceae } \\
\hline Aegiphila integrifolia (Jacq.) Moldenke & Pioneira & Zoo & Plantio \\
\hline \multicolumn{4}{|l|}{ Lauraceae } \\
\hline Nectandra megapotamica (Spreng.) Mez & Não Pioneira & Zoo & Plantio \\
\hline \multicolumn{4}{|l|}{ Lythraceae } \\
\hline Lafoensia glyptocarpa Koehne & Não Pioneira & Anemo & Plantio \\
\hline Lafoensia pacari A.St.-Hil. & Não Pioneira & Anemo & Plantio \\
\hline \multicolumn{4}{|l|}{ Malvaceae } \\
\hline Bastardiopsis densiflora (Hook. \& Arn.) Hassl. & Pioneira & Auto & Plantio \\
\hline Ceiba speciosa (A.St.-Hil.) Ravenna & Não Pioneira & Anemo & Plantio \\
\hline Guazuma ulmifolia Lam. & Pioneira & Zoo & Plantio \\
\hline Luehea divaricata Mart. \& Zucc. & Não Pioneira & Anemo & Plantio \\
\hline \multicolumn{4}{|l|}{ Meliaceae } \\
\hline Cedrela fissilis Vell. & Não Pioneira & Anemo & Planio \\
\hline Cedrela odorata $\mathrm{L}$. & Não Pioneira & Anemo & Planio \\
\hline Melia azedarach L.** & Exótica & Zoo & Regenerante \\
\hline \multicolumn{4}{|l|}{ Moraceae } \\
\hline Ficus enormis Mart. ex Miq. & Pioneira & Zoo & Plantio \\
\hline Maclura tinctoria (L.) D.Don ex Steud. & Não Pioneira & Zoo & Plantio \\
\hline \multicolumn{4}{|l|}{ Myrsinaceae } \\
\hline Myrsine umbellata Mart. & Pioneira & Zoo & Plantio \\
\hline \multicolumn{4}{|l|}{ Myrtaceae } \\
\hline Eugenia uniflora L. & Não Pioneira & Zoo & Plantio \\
\hline Psidium guajava L.** & Exótica & Zoo & Plantio \\
\hline Eucalyptus sp. ${ }^{* *}$ & Exótica & N.C. & Regenerante \\
\hline \multicolumn{4}{|l|}{ Phytolaccaceae } \\
\hline Gallesia integrifolia (Spreng.) Harms & Não Pioneira & Anemo & Plantio \\
\hline
\end{tabular}


Tabela 1 (continuação)

\begin{tabular}{|c|c|c|c|}
\hline Família/Espécie & Grupo Ecológico & Síndrome de Dispersão & Origem \\
\hline \multicolumn{4}{|l|}{ Polygonaceae } \\
\hline Triplaris americana $\mathrm{L}$. & Pioneira & Anemo & Plantio \\
\hline \multicolumn{4}{|l|}{ Rhamnaceae } \\
\hline Colubrina glandulosa Perkins & Não Pioneira & Zoo & Plantio \\
\hline Rhamnidium elaeocarpum Reissek & Não Pioneira & Zoo & Plantio \\
\hline \multicolumn{4}{|l|}{ Rosaceae } \\
\hline Prunus myrtifolia (L.) Urb. & Não Pioneira & Zoo & Plantio \\
\hline \multicolumn{4}{|l|}{ Rubiaceae } \\
\hline Genipa americana $\mathrm{L}$. & Não Pioneira & Zoo & Plantio \\
\hline \multicolumn{4}{|l|}{ Rutaceae } \\
\hline Balfourodendron riedelianum (Engl.) Engl. & Não Pioneira & Anemo & Plantio \\
\hline Dictyoloma vandellianum A.Juss. & Pioneira & Anemo & Plantio \\
\hline \multicolumn{4}{|l|}{ Salicaceae } \\
\hline Casearia cf. decandra Jacq. & Não Pioneira & Zoo & Plantio \\
\hline \multicolumn{4}{|l|}{ Urticaceae } \\
\hline Cecropia pachystachya Trécul & Pioneira & Zoo & Plantio \\
\hline \multicolumn{4}{|l|}{ Verbenaceae } \\
\hline Aloysia virgata (Ruiz \& Pav.) Juss. & Pioneira & Anemo & Plantio \\
\hline Citharexylum myrianthum Cham. & Pioneira & Zoo & Plantio \\
\hline
\end{tabular}

Croton floribundus e Citharexylum myrianthum apresentaram, respectivamente, segundo e terceiro maiores índices de importância, sendo os valores próximos para as duas espécies. As espécies que apresentaram um valor de VI entre 8 e 11 foram: Guazuma ulmifolia, Myrsine umbellata, Schizolobium parahyba e Astronium fraxinifolium.

A diversidade encontrada na RPPN foi alta, sendo o índice de diversidade de Simpson de 0,97 e de Shannon $\left(\mathrm{H}^{\prime}\right)$ de 3,87. O índice de equitatividade de Pielou $\left(J^{\prime}\right)$ foi 0,89 .

\section{Discussão}

Quando comparados os resultados obtidos no presente estudo, nove anos após o plantio, com o estudo realizado aos dois anos e meio após o plantio (Mandetta 2007), observou-se semelhança quanto à composição florística, com 63 espécies $(82,9 \%)$ em comum para os dois estudos. Em relação às demais, somam 13 novas espécies $(17,1 \%)$, sendo elas: Gochnatia polymorpha, Alchornea glandulosa, Handroanthus sp., Bauhinia sp., Anadenanthera colubrina var. cebil, Schizolobium parahyba, Aegiphila integrifolia, Lafoensia glyptocarpa, Bastardiopsis densiflora, Eucalyptus sp., Triplaris americana, Balfourodendron riedelianum, Dictyoloma vandellianum e Casearia $\mathrm{cf}$. decandra. Entre as novas espécies amostradas, apenas A. glandulosa e Eucalyptus sp. são espécies que não constam na lista de plantio, portanto, não foram plantadas, tendo surgido na área por regeneração natural.

Alchornea glandulosa foi considerada regenerante, devido à grande quantidade de indivíduos com porte arbóreo e indivíduos regenerantes de diferentes idades, distribuídos em toda RPPN. Essa espécie produz frutos pequenos, do tipo cápsulas, amplamente distribuídos por toda a copa, sendo muito atrativa à avifauna (Valente 2001, Pascotto 2006). Sua dispersão, no município de Mogi-Guaçu, já foi relatada por Mantovani et al. (1989), que observaram o surgimento de plântulas da espécie, a partir da dispersão de sementes. Embora Mandetta (2007) não tenha amostrado essa espécie em seu levantamento, acredita-se que a espécie tenha sido propagada pela avifauna local, nos primeiros anos após o estabelecimento do dossel, o que tem contribuído na inclusão de indivíduos dessa espécie para os estratos arbóreo e regenerante.

Em relação às espécies que constam no levantamento realizado por Mandetta (2007) e não constam no presente estudo, ocorreram 20 espécies, sendo 10 não pioneiras (Handroanthus $\mathrm{cf}$. 
chrysotrichus, Cordia superba, Bauhinia forficata, Erythrina falcata, Lonchocarpus muehlbergianus, Leucochloron incuriale, Cariniana estrellensis, Cariniana legalis, Eugenia brasiliensis e Zanthoxylum rhoifolium); seis pioneiras (Trema micrantha, Tibouchina granulosa, Heliocarpus popayanensis, Eugenia brasiliensis, Triplaris gardneriana e Solanum granulosoleprosum); três exóticas (Tabebuia pentaphylla, Bauhinia variegata e Leucaena leucocephala) e uma não classificada (Tabebuia sp.). Acredita-se que essas espécies não foram contempladas no presente estudo, principalmente por ainda não terem atingido o CAP suficiente para entrar no levantamento, no entanto, também considera-se que algumas espécies apenas não se encontravam dentro das subparcelas amostrais.

Em relação às famílias, nota-se que as mais diversas foram Fabaceae, Bignoniaceae e Anacardiaceae, correspondendo às mesmas famílias encontradas por Mandetta (2007). Em relação às áreas naturais conservadas, próximas à área de estudo, também no município de Mogi-Guaçu, (Gibbs \& Leitão-Filho 1978), a família mais diversa foi Fabaceae. Mantovani et al. (1989), com base em estudos também desenvolvidos no mesmo município, observaram que as famílias mais diversas foram Fabaceae, Myrtaceae e Lauraceae.

Segundo Mantovani et al. (1989), em seus estudos no município de Mogi-Guaçu, foram observadas com elevado valor de importância (VI) as espécies

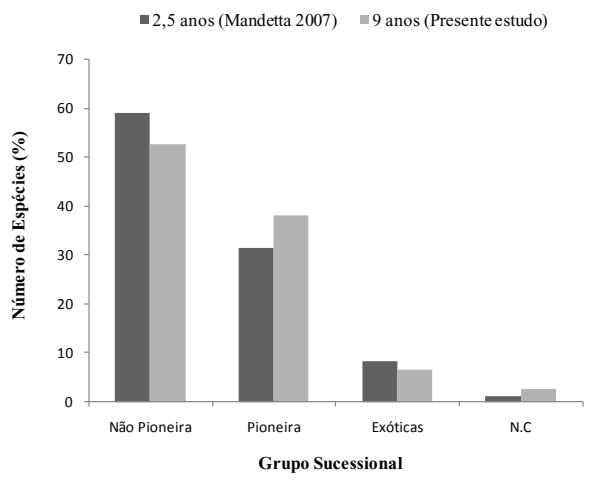

Figura 2. Grupos sucessionais dos dois estudos desenvolvidos na RPPN Parque São Marcelo, Mogi-Guaçu, SP, Brasil, com dois anos e meio (Mandetta 2007) e nove anos após plantio (presente estudo). N.C.: Não Classificadas, - 2,5 anos (Mandetta 2007), - 9 anos (Presente estudo).

Figure 2. Successional groups of two studies developed at PRNP Parque São Marcelo, Mogi-Guaçu, São Paulo State, Brazil, with two years and a half(Mandetta 2007) and nine years after planted (present study). N.C.: Not Classified, $\mathbf{- 2 . 5}$ years (Mandetta 2007), - 9 years (present study).
Alchornea grandulosa, Inga vera, Croton urucurana, Croton floribundus, Nectandra megapotamica, Myrsine umbellata, Guazuma integrifolia, Cecropia pachystachya e Copaifera langsdorfii, que ocorrem naturalmente na mata ciliar do rio Mogi-Guaçu. Em área com menor influência da vegetação ciliar, observa-se presença de Lithraea molleoides, Myrsine coreacea, Casearia decandra, Hymenaea courbaril, Handroanthus ochraceus, Matayba elaegnoides, Tapirira guianensis e Copaifera langsdorfii. É importante mencionar a semelhança da composição florística da RPPN com áreas próximas, destacando-se o aumento na conservação das espécies que ocorrem na região.

Mantovani et al. (1989) destacaram a influência do Cerrado nas formações vegetais, em áreas naturais, localizadas no município de Mogi-Guaçu. Foram encontradas várias espécies na RPPN, que são comuns em área de Cerrado (lato sensu), mas ressalta-se que são espécies florestais de ampla distribuição, não sendo endêmicas desse bioma. Entre elas encontram-se: Croton floribundus, Guazuma ulmifolia, Myrsine umbellata, Astronium fraxinifolium, Handroanthus heptaphyllus, Schinus terebinthifolius, Tapirira guianensis e Jacaranda cuspidifolia. Dessa forma, observa-se que, no plantio da RPPN, considerou-se a transição entre Floresta Estacional Semidecídua e Cerrado (lato sensu), havendo, na composição florística da RPPN, espécies que ocorrem em ambas as formações florestais.

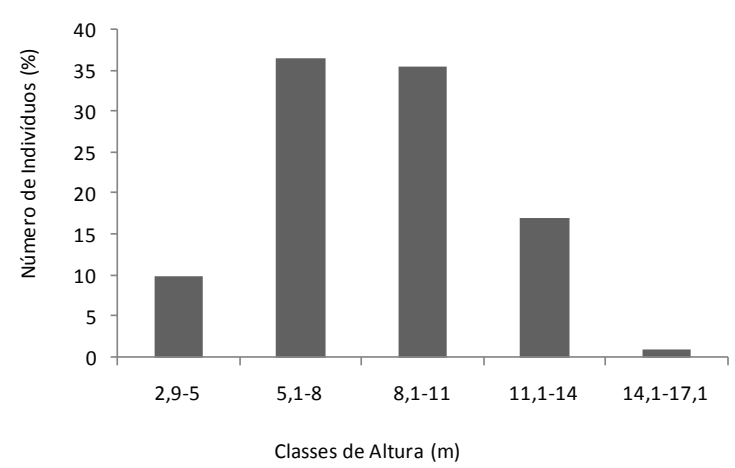

Figura 3: Indivíduos arbóreos amostrados nas 20 subparcelas amostrais da RPPN Parque São Marcelo, Mogi-Guaçu, SP, Brasil, distribuídos de acordo com a classe de altura (m), expressa em porcentagem.

Figure 3: Woody specimens obtained from 20 sub-plots located at PRNP Parque São Marcelo, Mogi-Guaçu, São Paulo State, Brazil, according to height class distribution (m), expressed in percentage. 
Tabela 2. Parâmetros fitossociológicos para as espécies do estrato arbóreo, amostradas nas 20 subparcelas amostrais da RPPN Parque São Marcelo, Mogi-Guaçu, SP, Brasil. FR: Frequência Relativa; DoR: Dominância Relativa; AR: Abundância Relativa; VC: Valor de Cobertura; VI: Valor de Importância; **Espécies exóticas.

Table 2. Phytosociological parameters of woody overstory, obtained from 20 sub-plots located at RPPN Parque São Marcelo, Mogi-Guaçu, São Paulo State, Brazil. FR: Relative Frequency; DoR: Relative Dominance; AR: Relative Abundance; VC: Cover Value; VI: Importance Value.**Exotic species.

\begin{tabular}{|c|c|c|c|c|c|}
\hline Espécies & FR & DoR & AR & $\mathrm{VC}$ & VI \\
\hline Inga vera subsp. affinis (DC.) T.D. Penn. & 6,64 & 21,66 & 10,56 & 32,22 & 38,86 \\
\hline Croton floribundus Spreng. & 3,91 & 9,62 & 4,72 & 14,34 & 18,24 \\
\hline Citharexylum myrianthum Cham. & 5,08 & 8,24 & 4,72 & 12,96 & 18,04 \\
\hline Guazuma ulmifolia Lam. & 2,34 & 4,35 & 3,61 & 7,96 & 10,31 \\
\hline Myrsine umbellata Mart. & 4,30 & 1,52 & 4,17 & 5,69 & 9,99 \\
\hline Schizolobium parahyba (Vell.) Blake & 1,56 & 6,30 & 1,11 & 7,41 & 8,97 \\
\hline Astronium fraxinifolium Schott & 2,73 & 2,37 & 3,33 & 5,70 & 8,44 \\
\hline Handroanthus heptaphyllus Mattos & 2,34 & 0,87 & 4,17 & 5,03 & 7,38 \\
\hline Peltophorum dubium (Spreng.) Taub. & 2,34 & 2,12 & 2,78 & 4,90 & 7,24 \\
\hline Astronium graveolens Jacq. & 2,73 & 1,30 & 2,50 & 3,80 & 6,53 \\
\hline Schinus terebinthifolius Raddi & 2,73 & 1,57 & 2,22 & 3,79 & 6,52 \\
\hline Tapirira guianensis Aubl. & 2,34 & 1,96 & 1,94 & 3,91 & 6,25 \\
\hline Psidium guajava L.** & 3,13 & 0,61 & 2,50 & 3,11 & 6,23 \\
\hline Cedrela fissilis Vell. & 1,95 & 2,10 & 1,67 & 3,76 & 5,72 \\
\hline Jacaranda cuspidifolia Mart. & 2,73 & 0,55 & 2,22 & 2,78 & 5,51 \\
\hline Mimosa bimucronata (DC.) Kuntze & 1,56 & 2,80 & 1,11 & 3,91 & 5,47 \\
\hline Tecoma stans (L.) Juss. ex Kunth** & 0,78 & 0,64 & 3,61 & 4,25 & 5,03 \\
\hline Maclura tinctoria (L.) D.Don ex Steud. & 1,95 & 1,55 & 1,39 & 2,94 & 4,90 \\
\hline Triplaris americana L. & 2,34 & 0,83 & 1,67 & 2,49 & 4,84 \\
\hline Cordia trichotoma (Vell.) Arráb. ex Steud. & 1,56 & 1,56 & 1,67 & 3,23 & 4,79 \\
\hline Pterogyne nitens Tul. & 1,17 & 2,45 & 1,11 & 3,56 & 4,73 \\
\hline Rhamnidium elaeocarpum Reissek & 1,95 & 0,79 & 1,94 & 2,74 & 4,69 \\
\hline Senna multijuga (Rich.) H.S. Irwin \& Barneby & 1,56 & 1,67 & 1,39 & 3,05 & 4,62 \\
\hline Albizia niopoides (Spruce ex Benth.) Burkart & 1,95 & 0,97 & 1,67 & 2,63 & 4,59 \\
\hline Myracrodruon urundeuva Allemão & 1,17 & 1,09 & 1,94 & 3,03 & 4,20 \\
\hline Colubrina glandulosa Perkins & 1,56 & 1,18 & 1,11 & 2,29 & 3,86 \\
\hline Alchornea glandulosa Poepp. \& Endl. & 0,78 & 2,35 & 0,56 & 2,91 & 3,69 \\
\hline Cordia abyssinica R. Br. ex A. Rich.** & 0,78 & 0,93 & 1,94 & 2,87 & 3,65 \\
\hline Cedrela odorata L. & 0,78 & 1,78 & 0,83 & 2,61 & 3,40 \\
\hline Gallesia integrifolia (Spreng.) Harms & 1,17 & 1,31 & 0,83 & 2,14 & 3,32 \\
\hline Cecropia pachystachya Trécul & 1,56 & 0,63 & 1,11 & 1,74 & 3,31 \\
\hline Schinus molle L. & 0,78 & 1,08 & 1,39 & 2,47 & 3,25 \\
\hline Senegalia polyphylla (DC.) Britton \& Rose & 1,56 & 0,42 & 1,11 & 1,53 & 3,09 \\
\hline Pterocarpus rohrii Vahl & 1,17 & 0,95 & 0,83 & 1,78 & 2,95 \\
\hline Poecilanthe parviflora Benth. & 1,56 & 0,17 & 1,11 & 1,28 & 2,84 \\
\hline Anadenanthera colubrina (Vell.) Brenan & 1,17 & 0,80 & 0,83 & 1,63 & 2,80 \\
\hline Cassia leptophylla Vogel & 0,78 & 1,05 & 0,56 & 1,61 & 2,39 \\
\hline Prunus myrtifolia (L.) Urb. & 1,17 & 0,37 & 0,83 & 1,20 & 2,37 \\
\hline
\end{tabular}


Tabela 2 (continuação)

\begin{tabular}{|c|c|c|c|c|c|}
\hline Espécies & FR & DoR & $\mathrm{AR}$ & $\mathrm{VC}$ & VI \\
\hline Lafoensia pacari A.St.-Hil. & 1,17 & 0,23 & 0,83 & 1,07 & 2,24 \\
\hline Copaifera langsdorffii Desf. & 1,17 & 0,21 & 0,83 & 1,04 & 2,21 \\
\hline Lafoensia glyptocarpa Koehne & 0,78 & 0,60 & 0,83 & 1,43 & 2,21 \\
\hline Melia azedarach L.** & 0,78 & 0,58 & 0,83 & 1,41 & 2,19 \\
\hline Handroanthus serratifolius (A.H.Gentry) S.Grose & 1,17 & 0,08 & 0,83 & 0,91 & 2,08 \\
\hline Parapiptadenia rigida (Benth.) Brenan & 0,78 & 0,62 & 0,56 & 1,18 & 1,96 \\
\hline Tabebuia roseoalba (Ridl.) Sandwith & 0,78 & 0,28 & 0,83 & 1,12 & 1,90 \\
\hline Mabea fistulifera Mart. & 0,78 & 0,53 & 0,56 & 1,09 & 1,87 \\
\hline Gochnatia polymorpha (Less.) Cabrera & 0,78 & 0,38 & 0,56 & 0,94 & 1,72 \\
\hline Ceiba speciosa (A.St.-Hil.) Ravenna & 0,78 & 0,32 & 0,56 & 0,88 & 1,66 \\
\hline Anadenanthera colubrina var. cebil (Griseb.) Altschul & 0,78 & 0,32 & 0,56 & 0,87 & 1,65 \\
\hline Bastardiopsis densiflora (Hook. \& Arn.) Hassl. & 0,39 & 0,65 & 0,56 & 1,20 & 1,59 \\
\hline $\begin{array}{l}\text { Hymenaea courbaril L. var. stilbocarpa (Hayne) Y.T. Lee \& } \\
\text { Langenh. }\end{array}$ & 0,78 & 0,23 & 0,56 & 0,79 & 1,57 \\
\hline Handroanthus impetiginosus Mattos & 0,78 & 0,20 & 0,56 & 0,75 & 1,54 \\
\hline Myroxylon peruiferum L.f. & 0,78 & 0,17 & 0,56 & 0,73 & 1,51 \\
\hline Tabernaemontana hystrix Steud. & 0,78 & 0,16 & 0,56 & 0,72 & 1,50 \\
\hline Lithrea molleoides (Vell.) Engl. & 0,78 & 0,13 & 0,56 & 0,69 & 1,47 \\
\hline Ficus enormis Mart. ex Miq. & 0,39 & 0,10 & 0,56 & 0,65 & 1,04 \\
\hline Aloysia virgata (Ruiz \& Pav.) Juss. & 0,39 & 0,30 & 0,28 & 0,58 & 0,97 \\
\hline Casearea decandra Jacq. & 0,39 & 0,19 & 0,28 & 0,47 & 0,86 \\
\hline Aegiphila integrifolia (Jacq.) Moldenke & 0,39 & 0,18 & 0,28 & 0,46 & 0,85 \\
\hline Enterolobium contortisiliquum (Vell.) Morong & 0,39 & 0,17 & 0,28 & 0,44 & 0,83 \\
\hline Luehea divaricata Mart. \& Zucc. & 0,39 & 0,13 & 0,28 & 0,41 & 0,80 \\
\hline Nectandra megapotamica (Spreng.) Mez & 0,39 & 0,11 & 0,28 & 0,39 & 0,78 \\
\hline Jacaranda mimosifolia D. Don** & 0,39 & 0,09 & 0,28 & 0,37 & 0,76 \\
\hline Handroanthus sp. & 0,39 & 0,08 & 0,28 & 0,36 & 0,75 \\
\hline Bauhinia sp.** & 0,39 & 0,07 & 0,28 & 0,35 & 0,74 \\
\hline Machaerium aculeatum Raddi & 0,39 & 0,07 & 0,28 & 0,34 & 0,74 \\
\hline Eucaliptus sp.** & 0,39 & 0,06 & 0,28 & 0,34 & 0,73 \\
\hline Genipa americana $\mathrm{L}$. & 0,39 & 0,05 & 0,28 & 0,33 & 0,72 \\
\hline Handroanthus ochraceus (Cham.) Mattos & 0,39 & 0,04 & 0,28 & 0,32 & 0,71 \\
\hline Croton urucurana Baill. & 0,39 & 0,03 & 0,28 & 0,31 & 0,70 \\
\hline Aspidosperma polyneuron Müll. Arg. & 0,39 & 0,03 & 0,28 & 0,30 & 0,69 \\
\hline Dictyoloma vandellianum A.Juss. & 0,39 & 0,03 & 0,28 & 0,30 & 0,69 \\
\hline Zeyheria tuberculosa (Vell.) Bureau ex Verl. & 0,39 & 0,03 & 0,28 & 0,30 & 0,69 \\
\hline Balfourodendron riedelianum (Engl.) Engl. & 0,39 & 0,03 & 0,28 & 0,30 & 0,69 \\
\hline Aspidosperma cylindrocarpon Müll. Arg. & 0,39 & 0,03 & 0,28 & 0,30 & 0,69 \\
\hline Eugenia uniflora L. & 0,39 & 0,03 & 0,28 & 0,30 & 0,69 \\
\hline
\end{tabular}

Foram encontradas espécies consideradas, de acordo com a lista de espécies ameaçadas de extinção do Estado de São Paulo (Mamede et al. 2007), como "vulneráveis", Myracrodruon urundeuva e Myroxylon peruiferum, e como "quase ameaçadas", Aspidosperma polyneuron, Copaifera langsdorffii e Balfourodendron riedelianum.

Segundo Melo \& Durigan (2007), os reflorestamentos têm mantido uma tendência na restauração dos aspectos funcionais, principalmente de matas 
ciliares, deixando a desejar na função da restauração e conservação da diversidade. Nesse aspecto, ressalta-se que há cinco espécies enquadradas em duas categorias de ameaça, como citado anteriormente, destacando a importância do reflorestamento da RPPN para a conservação dessas espécies e também da biodiversidade.

Considera-se que iniciativas de enriquecimento devem ser realizadas com espécies não pioneiras, ou seja, espécies de final de sucessão, em florestas que o dossel já esteja estabelecido, como no caso da RPPN. De modo complementar, sugere-se o uso de espécies que se enquadrem em alguma categoria de ameaça, de forma a promover sua conservação.

No entanto, deve-se sempre considerar a proporção em que essas espécies aparecem na natureza, evitando-se problema como pragas e doenças, que surgem quando indivíduos de uma espécie são plantados com alta densidade (Barbosa et al. 2011), ou quando plantados como monoculturas (Kageyama 2007). Nesse sentido, é importante conhecer a ecologia e como as espécies distribuem-se em ambientes naturais, para que qualquer intervenção na RPPN, como o enriquecimento, por exemplo, possa ser realizado com sucesso.

Em relação às espécies exóticas encontradas na RPPN, acredita-se que Cordia abyssinica e Jacaranda mimosifolia foram plantadas devido a um erro de identificação taxonômica das matrizes fornecedoras de sementes. Acredita-se que algumas espécies identificadas em nível de gênero no momento do plantio possam ser exóticas, como é o caso de Cordia abyssinica, como já foi relatado por Mandetta (2007).

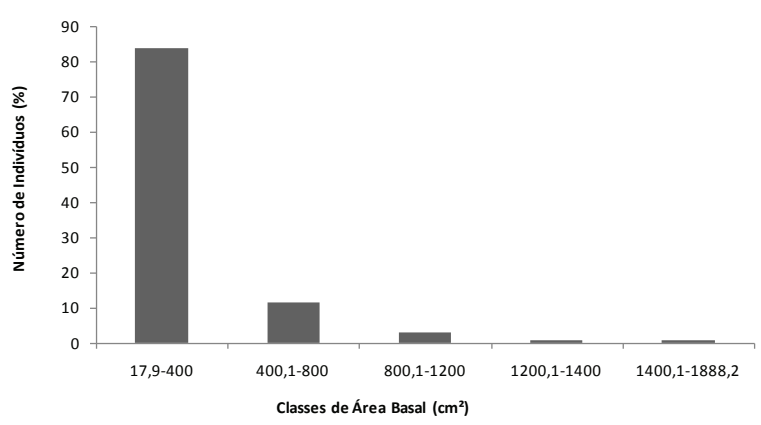

Figura 4. Indivíduos arbóreos amostrados nas 20 subparcelas amostrais da RPPN Parque São Marcelo, Mogi-Guaçu, SP, Brasil, distribuídos de acordo com a classe de área basal $\left(\mathrm{cm}^{2}\right)$, expressa em porcentagem.

Figure 4. Woody specimens obtained from 20 sub-plots located at PRNP Parque São Marcelo, Mogi-Guaçu, São Paulo State, Brazil, distributed according to basal area $\left(\mathrm{cm}^{2}\right)$, expressed in percentage.
Cordia abyssinica é originária da África e Ásia (Lorenzi et al. 2003), e segundo Durigan et al. (2010) foi amplamente utilizada em reflorestamentos no Estado de São Paulo, sendo confundida com outra espécie do mesmo gênero, $C$. superba, nativa do Brasil.

Outra espécie que provavelmente foi plantada erroneamente, Jacaranda mimosifolia, é nativa do norte da Argentina e Bolívia, muito semelhante a Jacaranda cuspidifolia, espécie nativa que ocorre no centro-oeste, de São Paulo até o Paraná (Lorenzi 2008). Jacaranda mimosifolia, conhecida no Brasil como jacarandá mimoso, é utilizada em arborização urbana, principalmente nas regiões Sul e Sudeste, chegando a atingir 15 metros de altura (Costa et al. 2011).

Já a espécie $P$ sidium guajava (goiabeira) merece especial atenção, pois tem sido amplamente utilizada em reflorestamentos, constando na lista de plantio da RPPN. Essa espécie é considerada subespontânea no Brasil (Sobral et al. 2012), sendo que as espécies encontradas no país são cultivares e não a espécie silvestre (Pereira 1984). Essa espécie é natural da América Tropical, ocorrendo do sul do México ao norte da América do Sul (Soubihe Sobrinho \& Gurgel 1962). A goiabeira é muita atrativa para a fauna, devido à grande quantidade de frutos, podendo ser facilmente dispersa por possuir numerosas sementes. No entanto, o potencial invasor da espécie já foi observado em unidades de conservação (Zviejkovski et al. 2009).

Já outras exóticas que vêm se disseminando pela RPPN são Melia azedarach (santa-bárbara), espécie nativa da Índia (Guha \& Niji 1965, Araújo et al. 2009), e Tecoma stans (ipê-de-jardim), espécie nativa da América Central (Blum et al. 2008). Essas espécies, em especial a última, são consideradas grandes invasoras de áreas naturais (Siqueira 2002, Barbosa \& Pizo 2006, Renó et al. 2007).

Embora a maioria das espécies e dos indivíduos encontrados na RPPN seja nativa de ocorrência regional, com base em estudos realizados em matas no município de Mogi-Guaçu (Gibbs \& Leitão-Filho 1978, Mantovani et al. 1989, Aquino \& Barbosa 2009), as espécies exóticas merecem especial atenção, pois algumas podem tornar-se invasoras. $\mathrm{O}$ efeito dessas espécies, em ambientes naturais, é hoje a segunda maior causa de extinções no mundo, perdendo apenas para a perda e fragmentação de habitats (Bourscheid 
\& Reis 2010). Nesse sentido, essas espécies que possuem origem no plantio ou ocorreram naturalmente na RPPN, devem ser erradicadas, bem como as que ocorrem próximas à RPPN, pois atuam como fonte de propágulos, podendo espalhar-se pelo reflorestamento.

O predomínio de espécies não pioneiras, no estrato arbóreo (53,9\%), já foi observado por Mandetta (2007). Justifica-se esse fato, pois as espécies não pioneiras foram plantadas em maior proporção, $56 \%$, em relação às pioneiras, $37 \%$.

A importância de espécies pioneiras, na floresta, está ligada ao estabelecimento de hábitat propício para o desenvolvimento de espécies não pioneiras, que se desenvolvem em ambiente com menor luminosidade. No entanto, o presente estudo foi realizado em uma floresta formada a partir de um reflorestamento, em que indivíduos pioneiros e não pioneiros foram plantados simultaneamente, havendo crescimento simultâneo de espécies desses dois grupos sucessionais. Nesta situação, segundo Whitmore (1989), as espécies pioneiras possuem crescimento mais rápido do que as espécies não pioneiras, ocupando o dossel da floresta, sendo posteriormente substituídas por não pioneiras.

Outro fator importante, em uma área em processo de restauração, é a incorporação de biomassa, que pode ser avaliada em função da área basal, expressa pela Dominância Relativa (DoR), obtida a partir da análise fitossociológica (tabela 2). Entre as espécies que apresentaram maior DoR, estão cinco espécies pioneiras: Inga vera subsp. affinis, Croton floribundus, Citharexylum myrianthum, Guazuma ulmifolia e Schizolobium parahyba. Essas espécies pioneiras são responsáveis, juntas, por $50,2 \%$ da dominância relativa. As espécies pioneiras, de forma geral, contribuíram em $68,6 \%$ na área basal, enquanto as não pioneiras contribuíram em $27,7 \%$ do total. A importância de indivíduos e espécies pioneiros também está relacionada à contribuição significativa para o acúmulo de biomassa e, consequentemente, no acúmulo de matéria orgânica no ecossistema.

O acúmulo de área basal, entre dois anos e meio e nove anos, foi bastante significativo, pois passou de 9,47 $\mathrm{m}^{2} \mathrm{ha}^{-1}$ para $18,29 \mathrm{~m}^{2} \mathrm{ha}^{-1}$. Damasceno (2005) também observou um aumento de área basal que passou de $15,19 \mathrm{~m}^{2} \mathrm{ha}^{-1}$, aos seis anos, para $20,48 \mathrm{~m}^{2} \mathrm{ha}^{-1}$, aos 11 anos após o plantio.

Quando se compara a área basal do reflorestamento da RPPN com outros reflorestamentos, observa-se que a RPPN, aos nove anos, possui uma área basal adequada à sua idade, em comparação a reflorestamentos com idade semelhantes ou próximas, como observado para reflorestamentos com sete anos, 17,26 $\mathrm{m}^{2} \mathrm{ha}^{-1}$ (Melo \& Durigan 2007); com nove anos, 17,32 $\mathrm{m}^{2}$ ha $^{-1}$ (Melo \& Durigan 2007) e com 11 anos, 20,48 $\mathrm{m}^{2} \mathrm{ha}^{-1}$ (Damasceno 2005). No entanto, a densidade do plantio usada em cada reflorestamento pode interferir no cálculo da área basal, muito embora Melo \& Durigan (2007) também considerem a área basal como o melhor indicador para se avaliar uma comunidade e para comparar diferentes comunidades.

Já em relação à altura da vegetação da RRPN, esta dobrou em um período de seis anos e meio, sendo que a altura média passou de quatro para 8,4 metros. As árvores emergentes que chegavam a seis metros, presentes na RPPN aos dois anos e meio de idade, eram, predominantemente, Trema micrantha. No presente estudo, aos nove anos após o plantio, observou-se que a RPPN apresentou altura predominantemente entre cinco e 11 metros, com um dossel bem desenvolvido. Árvores emergentes, como Croton floribundus (capixingui) e Schizolobium parahyba (guapuruvu), superaram os 14 metros de altura, tendo o último ultrapassado 17 metros. Em um estudo realizado em floresta ombrófila densa, Arzzola (2011) também observou que, em uma área de regeneração natural, $C$. floribundus foi a espécie com maior crescimento, ultrapassando os 18 metros de altura, aproximadamente quatro anos após corte o raso. Esse fato ocorreu devido ao rápido crescimento das espécies pioneiras, em relação às demais, formando, predominantemente, o dossel da floresta, fato também verificado por Arzzola (2011). De acordo com Souza \& Batista (2004), a altura pode ser um bom descritor para a vegetação, desde que ainda esteja em desenvolvimento inicial. Os autores observaram que em reflorestamentos que possuem cerca de cinco anos, há um favorecimento da altura, em detrimento da área basal. Esse fato ocorre devido ao crescimento de espécies pioneiras, que proporcionam cobertura do solo e fechamento da copa. No entanto, os mesmos autores observaram que reflorestamentos, a partir de 10 anos, apresentam diferença de área basal em relação a reflorestamentos mais recentes, mostrando a importância desse parâmetro para florestas dessa idade.

Em relação à densidade de indivíduos, observa-se que houve uma redução no presente estudo, comparativamente com o de Mandetta (2007). Esse fato não corrobora com dados obtidos por Damasceno 
(2005), que observou o aumento da densidade de indivíduos ao longo de seis anos. Esse fato pode estar associado à diferença na metodologia de amostragem entre Mandetta (2007), realizado com dois anos e meio, e o presente estudo, realizado aos nove anos após o plantio. $\mathrm{O}$ critério de inclusão adotado por Mandetta (2007) foi a altura igual ou superior a um metro, incluindo, portanto, mais indivíduos do que o presente estudo, em que se consideraram indivíduos arbóreos apenas aqueles com CAP $\geq 15 \mathrm{~cm}$. Outro aspecto relevante é a pouca influência de novas espécies no estrato arbóreo da RPPN. Destaca-se que com a presença de novas espécies, seria possível inferir que a área estaria sendo influenciada por outras espécies diferente daquelas que se plantou, havendo o enriquecimento da área e, consequentemente, um aumento da densidade com novos indivíduos.

Vários aspectos interferem no processo de colonização de uma área em processo de sucessão, como presença de fragmentos próximos, banco de sementes, histórico do uso da área, entre outros (Denslow \& Guzman 2000, Guariguata \& Ostertag 2001, Chazdon 2003, Chazdon et al. 2007, Chazdon 2008, Rodrigues et al. 2011). Destaca-se ainda que, após o fechamento da copa nas florestas secundárias, as taxas de ciclagem de nutrientes e a produtividade tendem a ser altas (Guariguata \& Ostertag 2001). Saldarriaga et al. (1988) observaram que entre 60 e 80 anos após corte e queima, espécies típicas de florestas maduras começam a ocorrer em florestas secundárias e estimaram em torno de 190 anos, para que uma floresta secundária recupere a área basal e biomassa de uma floresta madura. Observa-se ainda que, em florestas maduras, as espécies tardias são mais abundantes e apresentam maior área basal do que em florestas secundárias. (Chazdon et al. 2010).

Já em reflorestamentos como a RPPN, o seu histórico de uso associado à ausência de banco de sementes e de fragmentos próximos determinaram a baixa influência de espécies regenerantes com $\mathrm{CAP} \geq 5 \mathrm{~cm}$, sendo a riqueza de espécies encontrada na área sujeita basicamente ao que se plantou. Já em relação aos parâmetros de estrutura, destaca-se que, embora sua vegetação tenha apresentado um crescimento dos parâmetros de estrutura como altura e área basal, ainda é necessário um longo período para que atinja parâmetros de área basal e densidade semelhantes a florestas maduras.

Em relação à síndrome de dispersão na RPPN, nota-se que as espécies zoocóricas não foram predominantes quanto à proporção de espécies, conforme se observa para florestas semidecíduas naturais (Morelatto \& Leitão-Filho 1992, Aquino \& Barbosa 2009). No entanto, observa-se que houve predominância em relação ao número de indivíduos para essa síndrome, que ocorreu devido à grande abundância de algumas espécies como Inga vera subsp. affinis, Citharexylum myrianthum e Myrsine umbellata.

Verificou-se que as espécies zoocóricas têm contribuído para a atração da fauna na RPPN, com a presença de animais potencialmente dispersores, como morcegos onívoros e frugívoros, conforme já constatado por Silveira et al. (2011) e Trevelin et al. (2013).

É importante destacar a importância das espécies zoocóricas, presentes na RPPN, que atraem a fauna, favorecendo a chuva de sementes e, consequentemente, contribuindo com o enriquecimento da área com novas formas de vida, o que pode facilitar a restauração (Melo \& Durigan 2007). No entanto, destaca-se que no estrato arbóreo ainda não há reflexo de forte influência de novas espécies, permitindo destacar que sua composição florística ainda está sujeita, predominantemente, ao que se plantou. Todavia, a importância da fauna, na dispersão de novas espécies na área, pode ser verificada na composição do estrato regenerante, conforme estudos de Colmanetti (2013), desenvolvidos na mesma área.

Destaca-se também a importância das espécies anemocóricas, que atuam como fonte de propágulos autóctones para a própria RPPN, e como fornecedoras de sementes para fragmentos próximos. As espécies anemocóricas foram influenciadas principalmente pela densidade de indivíduos pertencentes às espécies da família Bignoniaceae, como Handroanthus spp., Jacaranda spp. e Tecoma stans.

O clima e a sazonalidade encontrada em Mogi-Guaçu favorecem o desenvolvimento de espécies anemocóricas. Estas frutificam nos meses mais secos do ano, período em que ocorrem ventos fortes, o que favorece a dispersão de sementes (Morellato \& Leitão-Filho 1992, Reys et al. 2005). Em contrapartida, vale destacar que o ambiente da RPPN também favorece a propagação de Tecoma stans e Jacaranda mimosifolia, espécies invasoras encontradas na área. Estas espécies produzem grande quantidade de sementes, disseminando-se facilmente pela área em restauração, devendo, dessa forma, ser erradicadas. 
Em relação à presença das espécies autocóricas, expressiva no estrato arbóreo, representam mais que $20 \%$ das espécies, sendo influenciadas principalmente por espécies pertencentes à família Fabaceae. As espécies autocóricas são pouco representadas em florestas mesófilas (Morelatto \& Leitão-Filho 1992, Aquino \& Barbosa 2009). O fato da presença de espécies dessa síndrome de dispersão ser significativa deve-se ao fato da RPPN ter origem a partir de um reflorestamento, sendo sua composição determinada no momento do plantio.

Com base nos resultados obtidos a partir dos índices de Simpson e de Shannon, observa-se uma alta diversidade da RPPN, sendo próxima a áreas naturais do Estado de São Paulo (Durigan \& Leitão-Filho 1995, Rozza 1997), e superior a outros reflorestamentos realizados no Estado, com idades semelhantes ou superiores (Melo \& Durigan 2007, Castanho 2009). No entanto, observa-se que não é suficiente apenas reflorestar uma área com alta riqueza de espécies, mas também é necessário haver equitatividade na distribuição dos indivíduos, semelhante a áreas naturais do Estado de São Paulo, conforme verificado por Durigan \& Leitão-Filho (1995). Todavia, quando se comparam áreas de diferentes locais, mesmo que sejam de mesma formação florestal, deve-se sempre considerar o status de conservação de cada área, por exemplo, o que pode comprometer as comparações e levar a inferências incorretas.

Quando se observam as diferentes épocas após plantio da RPPN, nota-se que a diversidade de Shannon e equitatividade de Pielou são semelhantes 3,85 e 0,87 , respectivamente, encontradas aos dois anos e meio, e 3,87 e 0,89 , respectivamente, encontradas aos nove anos após o plantio. Apenas a riqueza diferiu, sendo encontradas 83 espécies, aos dois anos e meio, e 76 espécies, aos nove anos após o plantio. Atribui-se essa diferença aos diferentes critérios de inclusão adotados na amostragem dos dois estudos. Dessa forma, algumas espécies levantadas no primeiro levantamento ainda não atingiram porte arbóreo, para que fossem incluídas no presente estudo. Esse fato é observado principalmente em relação às espécies não pioneiras, sendo que foram levantadas 49 espécies desse grupo por Mandetta (2007) e 40 no presente estudo.

Tabarelli \& Mantovani (1999) observaram que, nas áreas em processo de sucessão, a riqueza e a diversidade são características que se recuperam antes de outros fatores, como a composição de guildas, composição florística e estrutura física, com exceção da densidade.

Esse modelo também é aplicável a áreas que estão em processo de restauração. No entanto, observa-se que a riqueza e diversidade são definidas no momento do plantio, podendo sofrer influências externas ao longo do tempo. Alguns fatores que exercem essas influências referem-se ao histórico de uso da área, à proximidade de remanescentes florestais naturais, à ação de animais dispersores no reflorestamento e à manutenção adotada para a área. No entanto, quando não há influência desses fatores, a diversidade do reflorestamento fica restrita ao que se plantou e, nesse contexto, é muito importante utilizar a alta diversidade nos plantios, de forma a proporcionar sustentabilidade ao reflorestamento ao longo do tempo (Rodrigues et al. 2011).

Parâmetros como a área basal, altura média e diversidade são bons descritores e podem ser utilizados como indicadores para o estágio e a qualidade da vegetação arbórea na RPPN. Com base nesses parâmetros, observa-se que o reflorestamento apresenta um estrato arbóreo bem desenvolvido. Todavia, observa-se que a floresta da RPPN ainda é recente, com apenas nove anos, e seu estrato arbóreo está majoritariamente caracterizado pela composição de espécies utilizadas no plantio. Em longo prazo, espera-se que parâmetros como riqueza e diversidade possam variar, em função dos fatores externos e da própria dinâmica da floresta.

\section{Agradecimentos}

Ao Conselho Nacional de Desenvolvimento Científico e Tecnológico - CNPq, pelas bolsas concedidas (Bolsa de produtividade, Processo 313388/2009, e Bolsa do Programa de PósGraduação IBt). Ao Programa de Pós-Graduação em Biodiversidade Vegetal e Meio Ambiente, ao Instituto de Botânica de São Paulo e a International Paper, pelo apoio logístico recebido. Aos colegas Regina Tomoko Shirasuna e Eduardo Luís Martins Catharino, pela contribuição na classificação sucessional e identificação das espécies. Aos demais colaboradores, pelo apoio e sugestões que contribuíram para a melhoria do trabalho: Miguel Magela, João Machado, Hilton Thadeu Zarate do Couto, Paulo Roberto Ortiz Torres, Samuel Barnuevo, Moacir Pinto de Godoy, Adão Barbosa, Dorvalino Pinto de Godoy e Elenice Eliana Teixeira. 


\section{Literatura citada}

APG III. 2009. An update of the Angiosperm Phylogeny Group classification for the orders and families of flowering plants: APG III. Botanical Journal of the Linnean Society 161: 105-121.

Aquino, C. \& Barbosa, L.M. 2009. Classes sucessionais e síndromes de dispersão de espécie arbóreas e arbustivas existentes em vegetação ciliar remanescente (Conchal, SP), como subsídio para avaliar o potencial do fragmento como fonte de propágulos para enriquecimento de áreas revegetadas no Rio Mogi-Guaçu, SP. Revista Árvore 33: 349-358.

Araújo, S.A.C., Teixeira, M.F.S., Dantas, T.V.M., Melo, V.S.P., Lima, F.E.S., Ricarte, A.R.F., Costa, E.C., \& Miranda, A.M. 2009. Usos potenciais de Melia azedarach L. (Meliaceae): um levantamento. Arquivos do Instituto Biológico 76:141-148.

Aronson, J. 2010. What can and should be legalized in ecological restoration? Revista Árvore 34: 451-454.

Aronson, J., Brancalion, P.H.S., Durigan, G., Rodrigues, R.R., Engel, V.L., Tabarelli, M., Torezan, J.M.D., Gandolfi, S., Melo, A.C.G., Kageyama, P.Y., Marques, M.C.M., Nave, A.G., Martins, S.V., Gandara, F.B., Reis, A., Barbosa, L.M. \& Scarano, F.R. 2011. What role should government regulation play in ecological restoration? Ongoing debate in São Paulo State, Brazil. Restoration Ecology 19: 690-695.

Arzzola, F.A.R.P. 2011. Florestas secundárias e a regeneração de natural de clareias antrópicas na serra da Cantareira, SP. Tese de Doutorado, Universidade Estadual de Campinas, Campinas.

Barbosa, L.M. \& Barbosa, K.C. 2007. Restauração de matas ciliares - "Bases técnico - científicas como subsídios para Políticas Públicas sobre restauração de Matas Ciliares". In: L.M. Barbosa \& N.A. Santos Junior (orgs.). A botânica no Brasil: pesquisas, ensino e políticas públicas ambientais, São Paulo, pp. 619-630.

Barbosa, L.M., Barbosa, T.C. \& Barbosa, K.C. 2011. Ferramentas disponíveis visando à restauração ecológica de áreas degradadas: contribuição do Instituto de Botânica de São Paulo da Secretaria do Meio Ambiente. In: L.M. Barbosa (coord.). Anais do IV Simpósio de Restauração Ecológica, São Paulo, pp. 111-118.

Barbosa, L.M., Barbosa, T.C., Barbosa, K.C. \& Parajara, F.C. 2012. Práticas e políticas públicas para a restauração ecológica a partir de reflorestamentos com alta diversidade de espécies regionais. In: S.V. Martins (ed.). Restauração ecológica de ecossistemas degradados. Editora UFV, Viçosa, pp. 240-261.

Barbosa, K.C. \& Pizo, M.A. 2006. Seed Rain and Seed Limitation in a Planted Gallery Forest in Brazil. Restoration Ecology 14: pp. 504-515.
Blum, C.T., Borgo, M. \& Sampaio, A.C.F. 2008. Espécies invasoras na arborização de vias públicas de Maringá PR. Revista SBAU 3:78-97.

Bourscheid, K. \& Reis, A. 2010. Dinâmica da invasão de Pinus elliottii Engelm. em restinga sob processo de restauração ambiental no Parque Florestal do Rio Vermelho, Florianópolis, SC. Biotemas 23: 23-30.

Brancalion, P.H.S., Viani, R.A.G., Rodrigues, R.R.R. \& Gandolfi, S. 2012. Avaliação e monitoramento de áreas em processo de restauração. In: S.V. Martins (ed.) Restauração ecológica de ecossistemas degradados. Editora UFV, Viçosa, pp. 262-293.

Castanho, G.G. 2009. Avaliação de dois trechos de uma Floresta Estacional Semidecidual restaurada por meio de plantio, com 18 e 20 anos, no Sudeste do Brasil. Dissertação de Mestrado, Universidade de São Paulo, Piracicaba.

Chazdon, R.L. 2003. Tropical forest recovery: legacies of human impact and natural disturbances. Perspective in Plant Ecology, Evolution and Systematics 6: 51-71.

Chazdon, R.L., Letcher, S.G., Breugel M., MartínezRamos, M., Bongers, F., Finegan, B. 2007. Rates of change in tree communities of secondary neotropical forests following major disturbances. Philosophical Transactions of Royal Society B 362: 273-289.

Chazdon, R.L. 2008. Beyond Deforestation: Restoring Forests and Ecosystem Services on Degraded Lands. Science 320: 1458-1460.

Chazdon, R.L., Finegan, B., Capers, R.S., SalgadoNegret, B., Casanoves, F., Boukili, V. \& Norden, N. 2010. Composition and dynamics of functional groups of trees during tropical forest succession in Northeastern Costa Rica. Biotropica 42: 31-40.

Colmanetti, M.A.A. 2013. Estrutura da vegetação e características edáficas de um reflorestamento com espécies nativas. Dissertação de Mestrado, Instituto de Botânica, São Paulo.

Costa, R.S., Ortolani, F.A., Môro, F.V. \& Paulo, R.C. 2011. Caracterização morfológica de folhas e flores de espécies de Jacaranda (Bignoniaceae), cultivadas em Jaboticabal - SP. Revista de Biologia e Ciências da Terra 11: 169-181.

Damasceno, A.C.F. 2005. Macrofauna edáfica, regeneração natural de espécies arbóreas, lianas e epífitas em florestas em processo de restauração com diferentes idades no pontal do Paranapanema. Dissertação de Mestrado, Universidade de São Paulo, Piracicaba.

Denslow, J. \& Guzman, G.G. 2000. Variation in stand structure, light and seedling abundance across a tropical moist forest chronosequence, Panama. Journal of Vegetation Science 11: 201-212. 
Durigan, G., Engel, V.L. Torezan, J.M., Melo, A.C.G., Marques, M.C.M., Martins, S.V., Reis, A. \& Scarano, F.R. 2010. Normas jurídicas para a restauração ecológica: uma barreira a mais a dificultar o êxito das iniciativas? Revista Árvore 34: 471-485.

Durigan, G. \& Leitão-Filho, H.F. 1995. Florística e fitossociologia de matas ciliares do oeste paulista. Revista do Instituto Florestal 7: 197-239.

Forzza, R.C., Costa, A., Walter, B.M.T., Pirani, J.R., Morim, M.P., Queiroz, L.P., Martinelli, G., Peixoto, A.L., Coelho, M.A.N., Baumgratz, J.F.A., Stehmann, J.R., Lohmann, L.G. \& Hopkins, M. 2012. Angiospermas in Lista de Espécies da Flora do Brasil. Jardim Botânico do Rio de Janeiro, Rio de Janeiro. http://floradobrasil.jbrj.gov.br/2010/ (acesso em 03.2012).

Gibbs, P.E. \& Leitão-Filho, H.F. 1978. Floristic composition of an area of gallery near Mogi-Guaçu, state of São Paulo, S.E. Brazil. Revista Brasileira de Botânica 1: 151-156.

Guariguata, M.R. \& Ostertag, R. 2001. Neotropical secondary forest succession: changes in structural and functional characteristics. Forest Ecology and Management 148: 185-206.

Guha, S.R.D. \& Neji, J.S. 1965. Writing and printing paper from Melia azedarach Linn (Persian lilac). Indian Forest 91: 867-869.

Kageyama, P.Y. 2007. A biodiversidade como ferramenta em agroecossistemas. In: L.M. Barbosa \& N.A. Santos Jr. (orgs.). A botânica no Brasil: pesquisa, ensino e políticas públicas ambientais, Sociedade Botânica do Brasil, São Paulo, pp. 83-87.

Köpen, W. 1948. Climatologia. México: Fondo de Cultura Económica.

Kronka, J.F.N., Nalon, M.A., Matsukuma, C.K., Pavão, M., Kanashiro, M.M., Ywanw, M.S.S.I., Lima, L.M.P.R., Baitello, J.B., Borgo, S.C., Monteiro, C.H.B., Pontinha, A.A.S., Guillaumon, J.R., Joly, C.A. \& Couto, H.T.Z. 2005. Inventário florestal da vegetação natural do Estado de São Paulo. Imprensa Oficial, São Paulo.

Lorenzi, H. 2008. Árvores brasileiras: manual de identificação e cultivo de plantas arbóreas nativas do Brasil. 5 ed. Editora Plantarum, Nova Odessa.

Lorenzi, H. Souza, H.M., Torres, M.A.V. \& Bacher, L.B. 2003. Árvores exóticas no Brasil: madeireiras, ornamentais e aromáticas. Editora Plantarum, Nova Odessa.

Magurran, A.E. 2004. Measuring biological diversity. Blackwell Publishing, Oxford.

Mamede, M.C.H., Souza, V.C., Prado, J., Barros, F., Wanderley, M.G.L. \& Rando, J.G. 2007. Livro vermelho das espécies vegetais ameaçadas de extinção no Estado de São Paulo. Imprensa Oficial, São Paulo.
Mandetta, E.C.N. 2007. Avaliação florística e de aspectos da estrutura da comunidade de um reflorestamento com dois anos e meio de implantação no município de MogiGuaçu/SP. Dissertação de Mestrado, Universidade Estadual Paulista, Rio Claro.

Mantovani, W., Rossi, L., Romaniuc Neto, S., AssadLudewings, I.Y., Wanderley, M.G., Melo, M.M.R.F. \& Toledo, C.B. 1989. Estudo fitossociológico de áreas de mata ciliar em Mogi-Guaçu, SP, Brasil. In: L.M Barbosa (coord.). Simpósio sobre mata ciliar, Fundação Cargill, São Paulo, pp. 235-267.

Martins, S.V., Rodrigues, R.R., Gandolfi, S. \& Calegari, L. 2012. Sucessão Ecológica: Fundamentos e aplicações na restauração de ecossistemas florestais. In: S.V. Martins (ed.). Ecologia de florestas tropicais do Brasil. 2 ed. Editora UFV, Viçosa, pp. 21-52.

Melo, A.C.G. \& Durigan, G. 2007. Evolução estrutural de reflorestamentos de restauração de matas ciliares no Médio Vale do Paranapanema. Scientia Florestalis 73: 101-111.

Missouri Botanical Garden's VAST (Vascular Tropicos) nomenclatural database - W3 Tropicos. http://www. tropicos.org (acesso em 03.2012).

Morellato, L.P.C. \& Leitão-Filho, H.F. 1992. Padrões de frutificação e dispersão na Serra do Japi. In: L.P.C. Morellato (org.). História natural da Serra do Japi: ecologia e preservação de uma área florestal no sudeste do Brasil. Editora Unicamp, Campinas/SP, pp. 112-140.

Mori, S.A., Silva, L.A.M., Lisboa, G. \& Coradin, L. 1985. Manual de Manejo do Herbário Fanerogâmico. CEPEC, Ilhéus.

Mueller-Dombois, D. \& Ellenberg, H. 1974. Aims and methods of vegetation ecology. John Wiley, New York.

Pascoto, M.C. 2006. Avifauna dispersora de sementes de Alchornea glandulosa (Euphorbiaceae) em uma área de mata ciliar no estado de São Paulo. Revista Brasileira de Ornitologia 14: 291-296.

Pereira, F.M. 1984. Rica e Paluma: novas cultivares de goiabeira. In: Anais do Congresso brasileiro de Fruticultura, Florianópolis, pp. 524-528.

Pielou, E.C. 1969. An introduction to mathematical ecology. Wiley, New York.

Pielou, E.C. 1975. Ecological diversity. Wiley InterScience, New York.

Renó, L.R., Moscheta, I.S. \& Braccini, A.L. 2007. Morfoanatomia do fruto e semente de amarelinho (Tecoma stans (L.) Kunth - Bignoniaceae). Revista Brasileira de Sementes 29: 18-30.

Reys, P., Galetti, M., Morellato, L.P.C. \& Sabino, J. 2005. Fenologia reprodutiva e disponibilidade de frutos de espécies arbóreas em mata ciliar no Mato Grosso do Sul. Biota Neotropica 5: 1-10.

Rodrigues, R.R., Gandolfi, S., Nave, A.G.; Aronson, J., Barreto, T.E., Vidal C.Y. \& Brancalion, P.H.S. 2011. Large-scale ecological restoration of high-diversity tropical forests in SE Brazil. Forest Ecology and Management 261: 1605-1613. 
Rodrigues, R.R., Lima, R.A.F., Gandolfi, S. \& Nave, A.G. 2009. On the restoration of high diversity forests: 30 years of experience in the Brazilian Atlantic Forest. Biological Conservation 142: 1242-1251.

Rozza, A.F. 1997. Florística, fitossociologia e caracterização sucessional em uma floresta semidecidual: mata da virgínia, Matão, SP. Dissertação de Mestrado, Universidade de Campinas, Campinas.

São Paulo. 2008. Resolução SMA no 8, de 31 de janeiro de 2008. Diário Oficial do Estado de São Paulo - Meio Ambiente, 01/02, pp. 31-32.

Saldarriaga, J.G., West, D.C., Tharp, M.L. \& Uhl, C. 1988. Long-term chronosequence of forest succession in the upper Rio Negro of Colombia and Venezuela. Journal of Ecology 76: 938-958.

Silveira, M., Trevelin, L., Port-Carvalho, M., Godoi, S., Mandetta, E.N. \& Cruz-Neto, A.P. 2011. Frugivory by phyllostomid bats (Mammalia: Chiroptera) in a restored area in Southeast Brazil. Acta Oecologica 37: 31-36.

Simpson, E.H. 1949. Measurement of diveristy. Nature 163: 688.

Siqueira, L.P. 2002. Monitoramento de áreas restauradas no interior do estado de São Paulo, Brasil. Dissertação de Mestrado, Universidade de São Paulo, Piracicaba.

Sobral, M., Proença, C., Souza, M., Mazine, F. \& Lucas, E. 2012. Myrtaceae. Lista de Espécies da Flora do Brasil. http://floradobrasil.jbrj.gov.br/jabot/ floradobrasil/FB171 (acesso em 08.08.2013).
Soubihe Sobrinho,J. \& Gurgel,J.T.A. 1962. Taxa de panmixia na goiabeira (Psidium guajava L.). Bragantia 21: 15-20.

Souza, F.M. \& Batista, J.L.F. 2004. Restoration of seasonal semideciduous forests in Brazil: influence of age and restoration design on forest structure. Forest Ecology and Management 191: 185-200.

Tabarelli, M. \& Mantovani, W. 1999. A regeneração de uma floresta tropical montana após corte e queima (São Paulo - Brasil). Revista Brasileira de Biologia 59: 239-250.

Trevelin, L.C., Silveira, M., Port-Carvalho, C., Homem, D.H. \& Cruz-Neto, A.P. 2013. Use of space by frugivorous bats (Chiroptera: Phyllostomidae) in a restored Atlantic forest fragment in Brazil. Forest Ecology and Management 291: 136-143.

Valente, R.M. 2001. Comportamento alimentar de aves em Alchornea glandulosa (Euphorbiaceae) em Rio Claro, São Paulo. Iheringia Série Zoologia 91: 61-66.

Whitmore, T. C. 1989. Canopy gaps and the two major groups of forest trees. Ecology 70: 536-538.

Zviejkovski, I.P., Campos, J.B., Campos, R.M. \& Landgraf, G.O. 2009. Potencial invasor de Psidium guajava. Em um intervalo de cinco anos (2002 - 2007) dentro de uma Unidade de Conservacão. In: W. Delitti (org.). Anais do IX Congresso de Ecologia do Brasil, São Lourenço, pp. 1-3. 
